\title{
Cultural Sharing Through Visual Art Exhibition 'Dalam Bingkai' by JSRB-UPSI with FSRD-ISBI
}

\author{
Muhamad Firdaus Ramli ${ }^{1}$, Rofidah Musa ${ }^{2}$, Norkhaizatul Erma Mohd Khairuddin ${ }^{3}$, \\ Nurazry Basiron ${ }^{4}$ \\ ${ }^{1,2,3}$ Department of Art and Design \\ ${ }^{4}$ Department of Creative Multimedia \\ Faculty of Arts, Computers \& Creative Industry, \\ Universiti Pendidikan Sultan Idris, Tanjong Malim, Perak, Malaysia \\ *firdaus.ramli@fskik.upsi.edu.my ${ }^{1}$
}

Received: 18 June 2020; Accepted: 19 November 2020; Published: 19 November 2020

To cite this article (APA): Ramli, M. F., Musa, R., Mohd Khairuddin, N. E., \& Basiron, N. (2020). Cultural Sharing Through Visual Art Exhibition 'Dalam Bingkai' by JSRB-UPSI with FSRD$\begin{array}{llll}\text { ISBI. EDUCATUM Sournal of S-34. } & \text { Sciences, 6(2), }\end{array}$ https://doi.org/10.37134/ejoss.vol6.2.3.2020

To link to this article: https://doi.org/10.37134/ejoss.vol6.2.3.2020

\begin{abstract}
The cultural sharing of artworks and the creation of visual art can be expressed through exhibitions and demonstrations of artistic involvement. The artistic exhibitions can facilitate the factors of appreciation and understanding of visual art culture. Through the field of visual arts program, artworks and creation was inspired by the Department of Art and Design, Faculty of Art, Computers and Creative Industry (FSKIK) in collaboration with the Faculty of Design and Design (FSRD), Indonesian Institute of Cultural Arts, Bandung (ISBI). The 'Dalam Bingkai' Visual Art Exhibition associates the influence of internal sensible factors on the construction of an artwork. Art and cultural contribution programs are generated to achieve the field-sharing approach and mechanism. The objectivity towards this article sharing is due to the knowledge of the artistic delivery in preferring the style and gaining the experiences based on the artwork requirements. The article addresses the inquiries related to the fundamental aspect of visual art and the extension of artistic fundamental practice demands. The article is also based on an exploration of the pragmatic factors of the artwork construction. The quality of the visuals art argument of reflection related to the quality of the artwork that opens up the success of the impact upon the acceptance and attention. The understanding of the cultural sharing can be associated with logical thinking and the perception of awareness in the artwork making. The concept of visual practice is related to the factors of observation that need to be defined through the perception of the artist. The methodology relates to the artwork collection in exhibition space that indicates the content in presenting at UPSI Art Gallery. The appointed exhibition curators express the visual description into the reality of the artwork making. The observation processes promote the data based such as from field notes, interviews, photos and video recordings. The understanding of the elements and principles of visual arts technically meant as guidance. The duration of the exhibition was four (4) days aimed at the impact of the subject of 'Dalam Bingkai' meaning. Visual art exhibitions and cultural programs through a collective of an artistic understanding contribute to the stress-free condition from the artist perspective.
\end{abstract}

Keywords: Artwork Making, Partnership, Art and Culture Exhibition 


\section{INTRODUCTION}

The appreciation and motivation in this article are solely based on the visual emotional connection to the environment in particular. The 'Dalam Bingkai' Visual Art Exhibition links the influence of internal sensory factors on the construction of an artwork. The artwork is related to a variety of factors that affect aspects of the abstract meaning from personal environment. Furthermore, the process along with the artistic environment opens up the value of materialism by Collins (2019) as a creative approach. This approach enhances the performance of the exhibition with its concept and aesthetic design. Subsequently, an artwork was developed to complement the presentation of the artist's experience in completing the art exhibition. However, several of the artist's interpretations were affected by the weakening of the compositional and interpersonal guides. The composition of the artwork in the construction procedure is not determined and needs to be improved. According to Ramli and Musa (2020), the creation and complications related to the cognitive aspects of the workings including natural physical interactions. For the most part, the artist can produce distinctive styles through the best possible manipulated the artwork patterns. Through the focus of direct observation and reflection, the experience of the authors and the presentation of this article is shared.

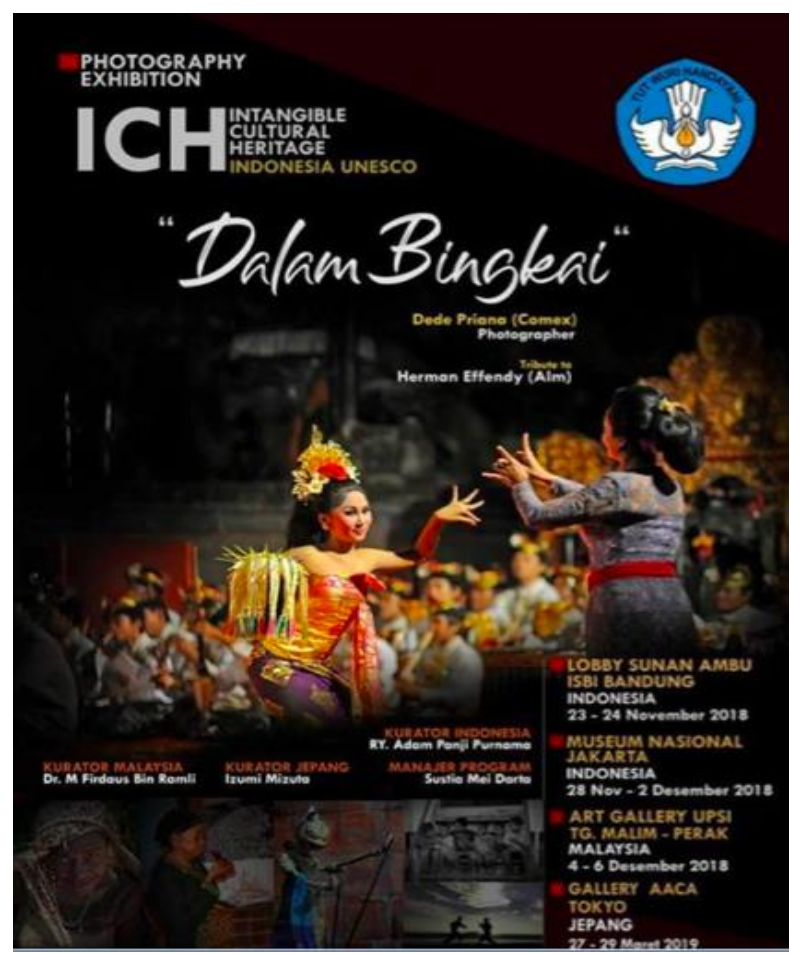

Figure 1: 'Dalam Bingkai 2018' Exhibition Poster

Reflections on the evaluation of the self-esteem performance of each artist in relation to the essential program of art and culture sharing performance are focused. The effective structuring can purify the artwork capacity in physical exhibition interaction in the field of art and cultural sharing. Figure 1 shows the 'Dalam Bingkai 2018' Exhibition Poster used to compose a special presentation. Wong (2019) explores that the sharing of exhibits, the differences between artistic and non-artistic methods in society as well as social would open the discussion. Additionally, it can be emphasized in the construction of the artwork through the need for the artist to understand the interrelationships used. The provision of space makes the conditions in the construction and sharing of an artwork respond to the physical and emotional aspects of artistic existence. 


\section{PROGRAM OBJECTIVES}

Art and cultural contribution programs are generated to achieve the field-sharing approach and mechanism:

1. To gain knowledge of the 'artwork delivery' and builds understanding in 'preferring' and 'constructing' the style (preface experience by the artist).

2. Organize the images categories and associate objectivity with personal experiences based on the artwork requirements.

\section{PROGRAM INQUIRIES}

The article addresses the following of inquiries related to:

1. What is the fundamental aspect of visual art to the needs of the artist's sensitivity to construct the artwork?

2. To what extent does the artist continue to pursue a fundamental understanding of the artistic program and cultural partnerships that meet the demands of their artwork?

\section{CULTURAL SOCIETY WORKSHOP}

The developed artwork should be associated to the dimensions and parameters based on the specific requirements of the creation theme. The practice is also based on an exploration of the pragmatic features of the artist. Furthermore, pragmatic existence is an influence to accept a perceptible artwork that gives them meaning. The level of the artistic quality of an artwork is related to the process of an existing person that can make conventions about a demand. According to Lauwrens (2019), the attention gained through sensory studies and artistic practice is emphasized by the importance of vision in the academic discourse in discipline speciality. Additionally, the need for the expansion of art and culture is to share an artwork which can highlight the individual's taste and personality by Musa, Ramli, Mohd Khairuddin and Abindinhazir (2019). With the initiation of the exhibition of the art and culture sharing program, it is possible to unite an aesthetic observation that specifically generate the artistic aspects.

Through artwork, the understanding of the distinguished artist's effort is given by the perception and cognition towards their existence which can be integrated. It presents the combination of sensational motivations and preparation factors in the creative aspect of the focused artwork prepared by the artists. The added value of an artwork exhibition context can also be related to the aspect of academic and art history (Frank-Witt's, 2020). This is because the artwork is traditionally interpreted to include time, location details and the intention of the artist to a wider context of their practices. Thereafter, at a certain matter, the artist needs to focus on the additional sensual or negative aspects of their artwork. It would reflect the sharing of artworks produced as an element of harmony or conflict to the future public. This is because of the importance and understanding needed for the artistic and cultural sharing program. Ramli and Musa (2020) point out that the artistic contribution would involve specific thinking in distinguishing the maturity of an artwork quality. The 'Dalam Bingkai' exhibition has raised the essential sustainability of visual arts as a significant factor in the construction of artworks as well as exposing the aesthetics field. 


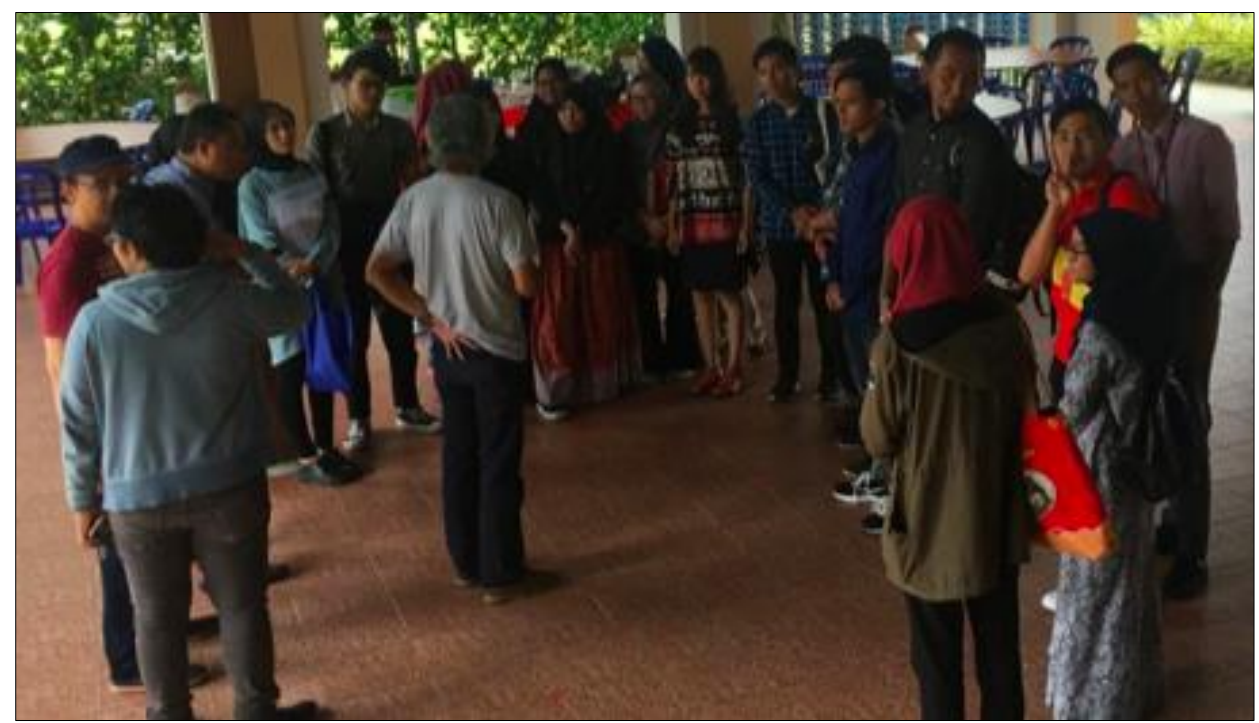

Figure 2: Initial Information Session from the Dean of the FSRD-ISBI

The knowledge of human and natural factors are related to the construction of artwork and construction. However, several artists are still trying to deliver the sensation and their personal feelings of the audience in a real (action) manner. Figure 2 shows the preliminary briefing session of the Dean of the FSRD-ISBI for the practised members' clarifications and actions. The briefing delegates the motivation towards emotional excitement of the artist being together in an artwork sharing exhibition. Practically every artist, designer, curator, educator and researcher needs to be committed to the practice of visual arts (Bradfield, 2020). Emotional excitement is influenced by excitement broadening the visual and aesthetic context. Nevertheless, at certain matter the artist concentration in visual and cultural work fails to manage, their artwork would lead to considerable provocation. As needed, the presentation of artwork should give a meaningful interpretation of the outcome of visual art.

\section{EXPERIENCE OF ARTISTIC EXHIBITION}

The understanding of personal and environmental representatives is associated with planning artwork and construction. However, several artists are still attempting to present the excitement and particular quality of the support in an exceptional manner. The manifests of the initial supervision session would guide the practised features of presentations and performances. The classification determines the passionate enthusiasm of the artist being collectively in an artwork sharing exhibition. Influencing sensation is inspired by the knowledge that broadening the visual and aesthetic meaning. Although at the particular circumstance the artist's concern in visual and cultural artwork would be neglected. The artwork does not accurately achieve the standard of the meaning and would lead to provocation issues. The performance of artwork should present a meaningful understanding of the visual arts.

\section{THOUGHT OF ART AND CULTURE}

The specific aesthetic aspects and creative domains are discussed by Christensen (2004) and Cupchik (1995). The appearance beyond the quality of the artwork construction is related to the visuals that can highlight the effectiveness of the artist's thinking quality. The argument of reflection related to the quality of the artwork that opens up the touches success upon the acceptance and attention. Observations of artworks meant for the aesthetics that carry the emotional terms and inner balance of life discussed by Salem, Nakatsu and Rauterberg (2006). 
The statements regarding 'experience in aesthetics' are as follows:

1. The sensitivity of the artist would be equivalent to the presentation of an artwork related to perception and meaning.

2. Cognitive and emotional of the sense that essential for an individual to understand an artwork presented by Cupchik (1995).

3. Actions and achievements of the artist approach to gain the understanding effort of the field exhibition.

The reflection of art and culture sharing has improved the artist's perspective towards 'element' of the artistic and field experiences. The understanding process and the emotional reflection of the artwork should be related to the unique thinking and understanding of the artist's mind by Ramli (2019). The artist needs to understand the expressive nature of an issue that is specifically considered for any respective exhibition theme. The artists personally needs to understand the symbolism of the exhibition's needs by the sharing for seeking of art and culture. According to Oman and Taylor (2018), the study of the value of attractive cultural activities for an institution raises the question of the status of exhibitions in academia. This aspect will shape the provision and delivery of the artist in developing the artwork for their exhibition. Therefore, the need for aesthetic knowledge is very important for the artist to be identified and evaluated. Aspects of the sincerity of the artwork making would relate to the senses, physical, management and the characters (theme) for the exhibition. The artist has to continue to construct their artwork by associating with factors that give their audience an edge and confidence. The audience understanding is an essential need for every artist in order to motivate their effort to develop the artwork as needed.

\section{EDUCATIONAL AND CULTURAL}

The understanding of the condition and cultural sharing can expose the important role of artwork development based on specific needs. The experiences an appreciation giving sensation features that established for the program technically. The efforts to strengthen an understanding of the artist and audience that necessary serve the living scenario. The creative 'interaction' process takes place and supports to enable the 'JSRB-FSRD Cultural Sharing' educational field. The quality and workmanship of a unique artwork creation are related to the aesthetics that are triggered. According to Kenning (2019), structure and culture are associated with critical art education values that offer the identity of an artist when they want to explore. The influence of the artist field knowledge is related and would enhance their taste. In this regard, the study associated with the logical thinking and the perception of awareness in the artwork making. The understanding of artistic nature and space does not have a fixed into reality and logical definition according to Merleau-Ponty's (1962) understanding. The essential structure and composition of artwork are related to the motives and issues that the artist must address. By creating a variety of things, the importance of an appreciation shows the importance of how the way the composition of a work is important. Merleau-Ponty (1962) adds to the formality of an unavailable image, it is not simply fit into the aspect of space.

The subjectivity of an individual of the artist would be impressed by the style, medium and the combination of senses. The integrated process of understanding about the artwork making would open up the subjectivity into the objectivity aspect. This understanding shapes intellectual thinking according to the natural priorities of the artwork. The artwork should be a necessity by stimulating the perceptions and thoughts of the artist who complements personal ideas and subjects. At certain condition, each unique visual masterpiece should be exposed for audient viewing. The artwork should be generated as visually based on the circumstances and needs of current issues as accordingly. The essence of the artistic matter should be 
complimented with the sincerity of the actual artwork that can be relied upon concerning the procedure of creative ability.

\section{VISUAL ART PRACTICE}

The specific artistic sharing of an individual's artwork is related to the concept of 'visual practice'. An individual's artist artwork is related to the factors of observation that need to be understood. An uncommon audience who is affected by the interaction of the mind of the artist relates to the presence of natural and physical experience. Observations leading to tangible complications according to Arnheim (1969) opened up conceptual thinking in ideas. Practising involves the behaviour and character of the individual artist character which should be associated with an artistic condition. The aspect of behaviour consciousness needs to be considered by an individual with the artistic potential of expression and action as shared by Gibson (1979) in theory (ability). The experience and relationships that are made available to the artistic field can be understood by the artist. The artist intuitive behaviour can be extended to a condition that is artistically practised. Access to the preparation of interesting visual images through the practice in visual artwork thought can be explained. The need for the artist to develop the artwork by focusing on the physical exhibition structure. The thoughts and minds shared with the 'meanings' show the individual's understanding of the subject to the artistic aspect. Performance can be enriched with field knowledge while optimizing the performance of the presentation (icon and image) of visual artwork. The success of the artwork can form a continuum of visual communication that bring the highest level of artistic delivery.

\section{METHODOLOGY}

The aesthetic and sensitivity aspects of the art and culture sharing program need to be understood and identified through the audience factors that address an artwork. The 'perception' of the artist in developing visual art is associated with intensified sensibility. The sharing of the 'Dalam Bingkai' artwork through the taste of the exhibition and the artistic range are combined. Froggett, Muller and Bennett (2019) point out that the challenge in developing a methodology that refers to the needs of the social experiences offered. The act of personal adaptation of an artist with a developmental and scholarly approach opens up the art and cultural program. The methodology indicating to this article practices is based on qualitative classification. The concept by the participant observation is also used to strengthen up the understanding of the overall situation from the visual arts program.

Additionally, the methodology of this article relates to the organisation collection of the artworks display into the exhibition space. The scope of the artwork for the exhibition includes the composition and expenditure of the space arrangement. The placement of the visual aspects indicates to the content in presenting visual art information. Exhibitions and showcase collections are shared within the physical environment of the UPSI Art Gallery. Interpretively, the artwork is presented in open-sharing sessions with academics, students, university visitors. The necessity and factors of 'mediation' by the willingness of a working artist to share art and culture need to be integrated. The JSRB-FSRD cultural sharing exhibition features display techniques as a way of communicating with gallery visitors. The appointed exhibition curators use the combination of lighting and props available in the showroom. Each artwork is expressed in combination with a visual description of the text to convey the reality of the artwork making. The image and subject aspects are intended to capture and anticipate specific feelings in the artwork.

Embedding the emotions into artwork that will generate and highlighting the unique needs. Approaches to address an article are based on exploration and associate to observations of artworks in exhibitions. The use of observation processes promotes shared data (field notes, interviews, photos and video recordings. In addition, the activities of the show are related to 
the understanding of the elements and principles of visual arts education. Technically, the duration of the exhibition is carried out by the artist for four (4) days, at the UPSI Art gallery space. By developing professional expertise, exhibiting the artist's ability to open up unique explorations and aims to impact the subject of 'Dalam Bingkai' exhibitions. The Exhibition by the students (artist) from FSKIK-ISBI through the display of this artwork collection, a document analysis approach is used to measure the evaluation of the shared artwork.

\section{THE SENSATION OF VISUAL ARTWORK}

The introductory of the value to an appreciation of the artwork concept have been related to the methodology in developing the contribution of visual art. The development of the speciality in the context of 'theme manipulation' and conceptualizes the idea of culture sharing. Aesthetic productivity is complemented by revealing and highlighting the process of inventiveness that exists as an original visual concept. Frost (2019) states that the focus on the artistic matter towards subjectivity was found to be away or mechanism that helps to reinforce the whole reality in visual art. The source for generating artistic insights is cleared to be used as the process that will be backed up for the theme. The artistic insight is used to indicates a set of expectation period by the artist that performing the resource search. The construction of the artistic matter can be integrated by identifying the sources and ideas of the artwork. The depth of artist personal experience is capable of meeting the external expressions of the visual arts exhibition. By adhering to the needs of the arts and cultural sharing program, the natural interaction of the artist will be influenced by the explorations of artistic learning.

Presentation of artworks by the artist is in the form of exploration and theme exposure:

1. Impressions of creative perception are influenced by 'dimensions' and space (element).

2. Sharing and solutions open up the 'meaning' and constructing the artwork.

3. Personal emotion is related to visual 'interaction'.

The transition between the process of the artist's interaction with the construction issue will be part of the strengths and functions of the theme. The emotional response of the artist through each of the artworks produced is stimulating. The initial phase of artwork will be generated according to the requirements of the social procedure. Nevertheless, Rowe (2020) views social perceptions on art issues as emphasizing the performance and process of conventional evaluation is looking at public and institutional effectiveness. The manipulation of the artwork pattern is determined by the artist's personals adaptation to the field of the physical exhibition as shared by the concept(s) and transformation. In several circumstances, specific emotional needs will act as a 'transforming' idea into an artwork image. This is part of the process of transforming the association of artistic and cultural sharing into an interactive medium.

\section{THE SIGNIFICANCE OF ART AND CULTURE ENCOURAGEMENT}

It's important to study about sharing visual art exhibitions and cultural programs trough a collective an artistic item. The understanding of realities and artistic through contribution by the artist is stress-free to be shared. The researchers are able to do the groundwork of visual art studies for education purposed. Knowing the understanding and identification of the behaviour of the artist personality has finalized the ideas phase of the artwork. The procedural requirements during the art and cultural exhibition phase program has determined the choice (theme) through the images with the audience. Furthermore, artists can understand the specific artistic aspects of education nature. The art exhibition is digitally recorded and documented for further reference. The partnerships in the essential experience of arts and culture sharing programs include a factor of acknowledging and accepting. The artist's gain and expand their 
analytical sensitivity towards exhibition space and physicality. Moreover, they learn about the environment and medium essential through the arts and culture sharing program. They were able to comprehend the principles of artistic matter in the relationship of the preparation exhibition artworks. The manipulation aspects of artwork patterns through composition and selection of image are being presented with personal styles. The concentrated needs of the artist to work together to produce a brief, collective description. The details of making as the initial sharing phase for artwork selection are focused. The suitability and natural state of nature of the artist were manipulated as a theme of choice. The artist interacts by applying their artwork theme is an essential of exhibition purpose. The collection of artworks to achieve the level of workmanship through observation of artistic and cultural exhibitions.

\section{CONCLUSION}

Researchers see that artists have high potential throughout the process of involvement in art and culture. However, in some cases, researchers are well aware of the condition several artists are still in the preliminary phase. The exhibition should be further strengthened with special guidance and non-verbal sharing from curators to manage and evaluate the findings of their work. There is most satisfying that secretarial establishments are working hard to find the most effective way of communicating knowledge. The arts and culture sharing program involves selected individuals who are trained as an artist. The artist develops their capabilities and brings the institution of study which always provides endless support. In particular, this article captures the field exhibition of the art and cultural sharing program as a document to share a concern audience. To achieve the optimum level, the entire organization of the joint program strives to meet the more scholarly art forms. Shared a memorable session during the opening ceremony of the JSRB-FSRD 'Dalam Bingkai' exhibition with the ISBI delegation and the Invitational Exhibit in Figure 3. Hopefully, this show will reference specific knowledge from the needs of all organizations in raising awareness of the arts and culture sharing program.

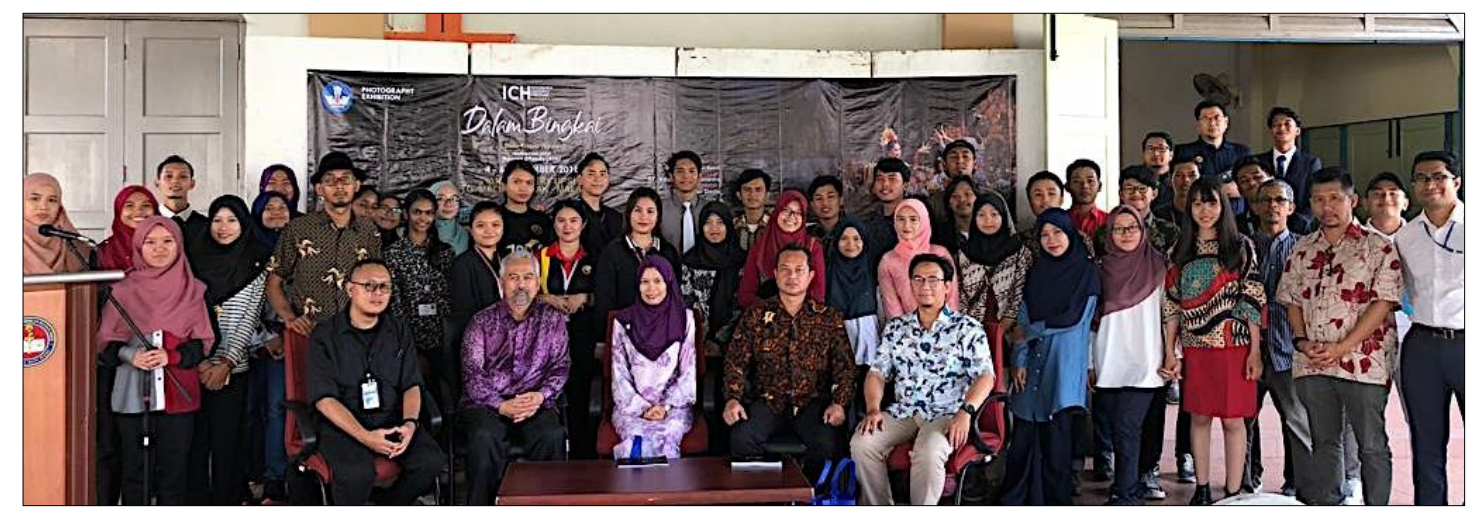

Figure 3: Memories Photo Session in Opening ceremony of JSRB-FSRD 'Dalam Bingkai' Exhibition with ISBI Delegation and Officiating Invitations

\section{ACKNOWLEDGMENT}

The authors would like to thank the entire JSRB exhibition organization, FSKIK Management and Visual Arts Association (PERSENI), UPSI and the FSRD-ISBI delegation who made the arts and cultural sharing program a success. The authors would like to express a special tribute to the 'Dalam Bingkai' exhibitors. 


\section{REFERENCES}

Arnheim, R. (1969). Visual Thinking. University of California press, Berkeley.

Bradfield, M. (2020). Ordinary extraordinary: the para/pata: institutionalism of Critical Practice. Journal of Visual Art Practice, 19:1, 38-52, DOI: $10.1080 / 14702029.2020 .1728049$

Christensen, M. S. (2004). Introducing Excitability. In Proceedings of the Nordic CHI 2004 Workshop, October 24, 2004, Tampere, Finland, pp. 10-13.

Collins, C.C. (2019). On posthuman materiality: art-making as rhizomatic rehearsal. Text and Performance Quarterly, 39:2, 153-159,

DOI: $10.1080 / 10462937.2019 .1595121$

Cupchik, G. C. (1995). Emotion in Aesthetics: reactive and reflective models, Poetics, vol. 23, pp. 177 188.

Frank-Witt, P. (2020). Intentionality in art: empirical exposure. Journal of Visual Art Practice, DOI: $10.1080 / 14702029.2020 .1752514$

Froggett, L., Muller, L., \& Bennett, J. (2019). The work of the audience: visual matrix methodology in museums. Cultural Trends, 28:2-3, 162-176, DOI: $10.1080 / 09548963.2019 .1617939$

Frost, S. (2019). A Complex Art of Logistics. Visual Culture in Britain, 20:1, 15-39, DOI: $10.1080 / 14714787.2019 .1576538$

Gibson, J. J. (1979). The Ecological Approach To Visual Perception. Houghton Mifflin, Boston.

Kenning, D. (2019). Art world strategies: neoliberalism and the politics of professional practice in fine art education. Journal of Visual Art Practice, 18:2, 115-131,

DOI: $10.1080 / 14702029.2018 .1500112$

Lauwrens, J. (2019). Touch as an aesthetic experience. Journal of Visual Art Practice, 18:4, 323-341, DOI: $10.1080 / 14702029.2019 .1680510$

Merleau-Ponty, M. (1962). Phenomenology of Perception. Routledge \& Kegan Paul, London.

Musa, R., Ramli, M., Mohd Khairuddin, N., \& Abindinhazir, Z. (2019). Eksplorasi lakaran bertema kenderaan serta kesan terhadap kreativiti kanak-kanak. KUPAS SENI: Jurnal Seni Dan Pendidikan Seni, 7, 72-80. Retrieved from http://ejournal.upsi.edu.my/index.php/JSPS/article/view/2708

Nagamachi, M. (2002). Kansei Engineering As A Powerful Consumer-Oriented Technology For Product Development. Applied Ergonomics, vol. 33, no. 3, pp. 289-294.

Oman, S., \& Taylor, M. (2018). Subjective well-being in cultural advocacy: a politics of research between the market and the academy. Journal of Cultural Economy, 11:3, 225-243, DOI: $10.1080 / 17530350.2018 .1435422$

Porr, M. (2019). Rock art as art. Time and Mind, 12:2, 153-164, DOI: 10.1080/1751696X.2019.1609799

Ramli, M. F. (2019). Argumentasi Terhadap Pergerakan Fesyen Jalanan Tempatan. KUPAS SENI: Jurnal Seni Dan Pendidikan Seni, 6. Retrieved from http://ejournal.upsi.edu.my/index.php/JSPS/article/view/2278 
Ramli, M. F., \& Musa, R. (2020). Ekplorasi seni visual melalui aktiviti lakaran asas terhadap kanakkanak prasekolah. Jurnal Pendidikan Awal Kanak-Kanak Kebangsaan, 9, 35-47. Retrieved from http://ejournal.upsi.edu.my/index.php/JPAK/article/view/3712

Rowe, C. (2020). The degree show may not be your best show. Journal of Visual Art Practice, 19:1, 5368 , DOI: $10.1080 / 14702029.2020 .1724664$

Salem, B., Nakatsu, R., \& Rauterberg, M. (2006). Kansei Experience. Aesthetic, Emotions, And Inner Balance.

Wong, S.K.S. (2019). Applying an ethological perspective of art to the community arts and socially engaged arts. Journal of Visual Art Practice, 18:3, 205-220, DOI: 10.1080/14702029.2019.1613614 